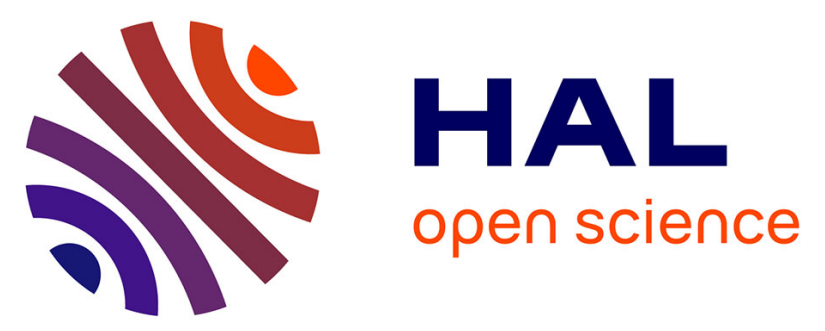

\title{
Comment on "Adsorption of hydrogen and hydrocarbon molecules on SiC(001)" by Pollmann et al. (Surf. Sci. Rep. 69 (2014) 55-104)
}

E. Wimmer, E. Celasco, L. Vattuone, L. Savio, A. Tejeda, M. Silly, M. d'Angelo, F. Sirotti, M. Rocca, A. Catellani, et al.

\section{To cite this version:}

E. Wimmer, E. Celasco, L. Vattuone, L. Savio, A. Tejeda, et al.. Comment on "Adsorption of hydrogen and hydrocarbon molecules on $\operatorname{SiC}(001)$ " by Pollmann et al. (Surf. Sci. Rep. 69 (2014) 55-104). Surface Science: A Journal Devoted to the Physics and Chemistry of Interfaces, 2016, 644, pp.L170 L171. 10.1016/j.susc.2015.08.025 . cea-01485574

\section{HAL Id: cea-01485574 https://hal-cea.archives-ouvertes.fr/cea-01485574}

Submitted on 9 Mar 2017

HAL is a multi-disciplinary open access archive for the deposit and dissemination of scientific research documents, whether they are published or not. The documents may come from teaching and research institutions in France or abroad, or from public or private research centers.
L'archive ouverte pluridisciplinaire HAL, est destinée au dépôt et à la diffusion de documents scientifiques de niveau recherche, publiés ou non, émanant des établissements d'enseignement et de recherche français ou étrangers, des laboratoires publics ou privés. 
Surface Science Letters

\title{
Comment on "Adsorption of hydrogen and hydrocarbon molecules on SiC(001)" by Pollmann et al. (Surf. Sci. Rep. 69 (2014) 55-104)
}

\author{
E. Wimmer ${ }^{\mathrm{a}, \mathrm{b}}$, E. Celasco ${ }^{\mathrm{c}, \mathrm{d}}$, L. Vattuone ${ }^{\mathrm{c}, \mathrm{d}}$, L. Savio ${ }^{\mathrm{d}}$, A. Tejeda ${ }^{\mathrm{e}, \mathrm{f}}$, M. Silly $^{\mathrm{e}}$, M. D'angelo ${ }^{\mathrm{g}}$, F. Sirotti ${ }^{\mathrm{e}}$, M. Rocca $^{\mathrm{c}, \mathrm{d}}$,
} A. Catellani ${ }^{\text {h }}$, G. Galli ${ }^{\mathrm{i}}$, L. Douillard ${ }^{\mathrm{j}}$, F. Semond ${ }^{\mathrm{k}}$, V.Yu. Aristov ${ }^{\mathrm{j}, \mathrm{l}}$, P. Soukiassian ${ }^{\mathrm{c}, \mathrm{e}, \mathrm{j}, *}$

a Materials Design Inc., Angel Fire, NM 87710, USA

b Materials Design SARL, 92120 Montrouge, France

c Istituto Materiali per Elettronica e Magnetismo, CNR, 16146 Genova, Italy

d Dipartimento di Fisica dell'Università di Genova, 16146 Genova, Italy

e Synchrotron SOLEIL, Saint-Aubin, 91192 Gif sur Yvette, France

${ }^{\mathrm{f}}$ CNRS, Laboratoire de Physique des Solides, 91405 Orsay, France

g INSP, CNRS UMR 7588, Université Pierre et Marie Curie, 75251 Paris, France

h S3-Nano, CNR, Via Campi 213 A, 41125 Modena, Italy

i The University of Chicago, 5801 South Ellis Avenue, Chicago, IL 60637, USA

j CEA-Saclay, DSM-IRAMIS-SPEC \& CNRS UMR 3680, 91191 Gif sur Yvette, France

k CNRS-CRHEA, Sophia-Antipolis, rue Bernard Grégory, 06560 Valbonne, France

${ }^{1}$ Institute of Solid State Physics, RAS, Chernogolovka, Moscow District 142432, Russia

\section{A R T I C L E I N F O}

Available online 2 September 2015

\section{Keywords:}

Nanotunnels

Nanochemistry

Silicon Carbide

Vibrational Properties

Electronic Properties

Atomic Structure

\begin{abstract}
A B S T R A C T
This comment clarifies two issues related to the (001) surface reconstructions of cubic SiC, namely: (i) The failure of the bridge-bond model for $\mathrm{H}$ atoms interacting with the $3 \mathrm{C}-\mathrm{SiC}(001) 3 \times 2$ reconstruction to explain all the experimental data based on different techniques, while a recent model has reconciled theory and experimental results. This model has not been discussed or even mentioned in the review by Pollmann et al.; and (ii) In their review, two models of the Si-terminated $\mathrm{c}(4 \times 2) 3 \mathrm{C}-\mathrm{SiC}(001)$ surface reconstruction are presented as equally probable. This is clearly not the case and the reasons are explained in this comment.
\end{abstract}

(C) 2015 Elsevier B.V. All rights reserved.
A review article entitled "Adsorption of hydrogen and hydrocarbon molecules on $\mathrm{SiC}(001)$ " by Johannes Pollmann, Xiangyang Peng, Jürgen Wieferinka and Peter Krüger has been published in the September-October 2014 issue of Surface Science Reports [1]. Based largely on their theoretical investigations, the authors describe in this document a topic of high current interest, namely the interaction of hydrogen and hydrocarbons with the various reconstructed cubic silicon carbide 3C$\mathrm{SiC}(001)$ surfaces. Given the importance of this topic and the purpose of such a review, it is necessary to present all relevant facts and findings, experimental as well as theoretical, in an objective and critical manner. While the review [1] contains a wealth of valuable information, there are omissions and problems in the way the results are presented, which need to be clarified. Specifically, this Comment addresses two issues, one related to the interaction of hydrogen with the $3 \mathrm{C}-\mathrm{SiC}(001) 3 \times 2$ surface and the second concerning the $3 \mathrm{C}-\mathrm{SiC}(001) \mathrm{c}(4 \times 2)$ reconstruction.

(1) The authors describe in this SSR report [1], their theoretical investigation (Lu, Krüger and Pollmann) of the $3 \times 2$ Si-rich reconstruction of

\footnotetext{
* Corresponding author at: CEA-Saclay, DSM-IRAMIS-SPEC \& CNRS UMR 3680, 91191 Gif sur Yvette, France.

E-mail address: patrick.soukiassian@cea.fr (P. Soukiassian).
}

the 3C-SiC(001) surface [2]. For this clean surface, they proposed the socalled Two Ad-layer Asymmetric Dimer (TAAD) model. The latter is in good qualitative agreement with the results of state-of-the-art experiments including atom-resolved scanning tunneling microscopy (STM) [3], optical anisotropy [4], synchrotron radiation-based grazing incidence X-ray diffraction (SR-GIXRD) [5] and photo-electron diffraction (SR-PED) [6], providing a TAAD-ALSD (Alternately Long and Short Dimers) model $[5,6]$. Here, experiment and theory are consistent. However, the discussion of the interaction of this surface with hydrogen fails to report key findings.

In the SSR review [1], the authors quote (Ref. [101]) and comment on an article on $\mathrm{H}$-induced $3 \mathrm{C}-\mathrm{SiC}(001) 3 \times 2$ surface metallization based on atom resolved STM, valence band photoemission spectroscopy (VB-PES) and vibrational spectroscopy using infrared absorption spectroscopy (IRAS) [7], and display some of its figures [1]. The authors discuss the bridge bond model and also point to their interesting earlier work on the reaction pathways of $\mathrm{H}$ adsorption on this $3 \mathrm{C}-\mathrm{SiC}(001)$ $3 \times 2$ surface, but do not mention that this model cannot explain all available experimental data such as the IRAS data [7]. This inconsistency has motivated an in-depth combined experimental and computational investigation, which has led to a new model consistent with all available experimental results. In fact, this work has paved the way to exciting 
new possibilities of surface functionalization through the opening of sub-surface nanotunnels [8]. This study was based on electronic and vibrational properties probed by both advanced experimental techniques, namely SR-PES and high-resolution electron energy losses spectroscopy (HREELS), and by state-of-the-art theoretical calculations [8]. The vibrational modes from the HREELS measurements [8] are in excellent agreement with previous IRAS measurements [7] and revealed the lack of any vibrational mode arising from $\mathrm{H}$ or $\mathrm{D}$ atoms in a bridge-bond between $\mathrm{Si}$ atoms in the third plane, as favored by earlier theoretical investigations [1,9-12]. In addition, such a bridge-bond position for $\mathrm{H}$ between two $\mathrm{Si}$ atoms in the third plane is also inconsistent with synchrotron radiationbased core-level photoemission spectroscopy (SR-CL-PES) experiments indicating an asymmetric charge transfer in the third atomic plane [13]. In contrast, the computed vibrational frequencies in Ref. [8] are in remarkable agreement with the HREELS measured data [8] originating from vibrational modes of $\mathrm{H}$ and $\mathrm{D}$ atoms passivating Si dangling bonds (created by the nanotunnel opening) in the third atomic layer below the surface dimers, but not for $\mathrm{H}$ or $\mathrm{D}$ atoms in a bridge position. Furthermore, the work of Ref. [8] provided novel insights into the understanding of the $\mathrm{H}$-induced metallization process including the occurrence of a semiconducting-metallic-semiconducting transition sequence. This work should have been included in this review, at least as a note added in proof, since it came out 11 months before the publication of the SSR [1].

(2) Describing the Si-terminated $\mathrm{c}(4 \times 2)$ reconstruction of the 3C-SiC(001) surface in Chapter 3.2, page 62, the authors report two models [1], namely the AUDD (Alternatively Up- and Down Dimer) model [14-21], "strongly favoured by experiment" and the MRAD (Missing-Row Asymmetric Dimer) model [22], "strongly favoured by theory". In the review [1], both models are presented as if they had equal probability to be correct. This is not the case.

The AUDD model is supported by a host of state-of-the-art experiments including atom-resolved STM [14-17], SR-PED [18] and synchrotron radiation-based SR-CL-PES [19], and also by valence band angleresolved photoemission spectroscopy (VB-ARPES) experiments [20] (omitted in the SSR [1]) determining the atomic and electronic structures of the Si-terminated c $(4 \times 2)$ reconstruction. Furthermore, the AUDD model is also supported by several state-of-the-art DFT, cluster and STM image calculations $[14,15,18,20,21]$ that are actually mentioned in the present SSR review article, but then, not considered in the discussion of the different models [1]. In fact, these DFT calculations reveal a great sensitivity of this reconstruction to strain and defects, which was also noted in experiments [23-25]. This $\mathrm{c}(4 \times 2)$ reconstruction corresponds to a single layer of $\mathrm{Si}$ atoms on a Si-terminated 3C-SiC(001) surface at room temperature, which turns into a $2 \times 1$ array upon low adsorbate exposures [23], contamination [24], or with increasing temperatures [25].

In contrast, the MRAD model is supported by a single DFT calculation $[1,22]$ assuming a higher Si coverage ( 1.5 monolayer) compared with the AUDD model. Notice that, adding Si atoms on top of the Si-terminated $c(4 \times 2)$ surface reconstruction (AUDD) invariably leads to the formation of self-organized $\mathrm{Si}$ atomic lines already at very low coverage [26]. The MRAD model was later dismissed because it failed to agree with SR-PED and other experiments when compared with the AUDD model [14-20]. Subsequently, the original article by Lu, Krüger and Pollmann [22] was the object of a comment on the MRAD model [27], with the related authors' answer appearing on the very next page of same issue of PRL [28]. However, while the SSR's authors are quoting as Ref. [95] their answer to this comment [28] of their SSR review article [1], they failed to quote the comment itself [27]. Finally, one should also notice that some of the authors of the SSR [1] (Peng, Krüger, Pollmann) have also published a theoretical investigation on $\mathrm{H}$ atoms interaction with the Si terminated $\mathrm{c}(4 \times 2)$ surface, focusing solely on the AUDD model, stating "Here, we concentrate on the AUDD model for simplicity" - see Chapter 3.2. in [29] - Ref. [138] in the SSR.

The problem of the stability of the Si-terminated 3C-SiC(001) $2 \times 1$ surface reconstruction, to which a significant part of this review [1] is devoted, also deserves some comments: this reconstruction can be experimentally obtained only via temperature-induced semiconducting $\mathrm{c}(4 \times 2) \Leftrightarrow$ metallic $2 \times 1$ reversible phase transition at $400{ }^{\circ} \mathrm{C}$ [25], or at room temperature upon low $\mathrm{H}_{2}$ exposures [23] or by background contamination [24] of the $\mathrm{c}(4 \times 2)$ reconstruction, the two latter inducing a $2 \times 1$ ordering of the 3 C-SiC(100) surface. Hence, such a $2 \times 1$ arrangement is not an intrinsic reconstruction of the clean Si-terminated 3C-SiC(001) surface [23-25].

In conclusion, the review [1] relies heavily on theoretical work. While the currently practiced level of theory, namely density functional theory, has made tremendous contributions to surface science by providing deep insights into the behavior of materials beyond the reach of current experiments and by stimulating new experiments, there are still a number of approximations involved, which introduce uncertainties, especially in subtle cases such as the $3 \mathrm{C}-\mathrm{SiC}(001) \mathrm{c}(4 \times 2)$ surface reconstruction.

Thus, we hope that with this Comment, the reader of SSR will have a more balanced and complete picture of our current understanding of the fascinating richness of $3 \mathrm{C}-\mathrm{SiC}(001)$ surfaces and the unique power of combining theory and experiment.

\section{References}

[1] J. Pollmann, X. Peng, J. Wieferink, P. Krüger, Surf. Sci. Rep. 69 (2014) 55.

[2] W. Lu, P. Krüger, J. Pollmann, Phys. Rev. B 60 (1999) 2495.

[3] F. Semond, P. Soukiassian, A. Mayne, G. Dujardin, L. Douillard, C. Jaussaud, Phys. Rev. Lett. 77 (1996) 2013.

[4] W. Lu, W.G. Schmidt, E.L. Briggs, J. Bernholc, Phys. Rev. Lett. 85 (2000) 4381.

[5] M. D'angelo, H. Enriquez, V.Yu. Aristov, P. Soukiassian, G. Renaud, A. Barbier, M. Noblet, S. Chiang, F. Semond, Phys. Rev. B 68 (2003), 165321.

[6] A. Tejeda, D. Dunham, F.J. García de Abajo, J.D. Denlinger, E. Rotenberg, E.G. Michel, P. Soukiassian, Phys. Rev. B 70 (2004), 045317.

[7] V. Derycke, P. Soukiassian, F. Amy, Y.J. Chabal, M. D'angelo, H. Enriquez, M.G. Silly, Nat. Mater. 2 (2003) 253.

[8] P. Soukiassian, E. Wimmer, E. Celasco, C. Giallombardo, S. Bonanni, L. Vattuone, L. Savio, M. Tejeda, M. Silly, F. D'angelo, F. Sirotti, M. Rocca, Nat. Com. 4 (2013) 2800.

[9] R. Di. Felice, C.M. Bertoni, C.A. Pignedoli, A. Catellani, Phys. Rev. Lett. 94 (2005), 116103.

[10] F.B. Mota, V.B. Nascimento, C.M.C. de Castilho, J. Phys. Condens. Matter 17 (2005) 4739 .

[11] H. Chang, J. Wu, B. Gu, F. Liu, W. Duan, Phys. Rev. Lett. 95 (2005), 196803.

[12] X. Peng, P. Krüger, J. Pollmann, Phys. Rev. B 72 (2005), 245320.

[13] M. D'angelo, H. Enriquez, N. Rodriguez, V.Yu. Aristov, P. Soukiassian, A. Tejeda, E.G. Michel, M. Pedio, C. Ottaviani, P. Perfetti, J. Chem. Phys. 127 (2007), 164716.

[14] P. Soukiassian, F. Semond, L. Douillard, A. Mayne, G. Dujardin, L. Pizzagalli, C. Joachim, Phys. Rev. Lett. 78 (1997) 907.

[15] L. Douillard, F. Semond, V.Yu. Aristov, P. Soukiassian, B. Delley, A. Mayne, G. Dujardin, E. Wimmer, Mater. Sci. Forum 264-268 (1998) 379.

[16] V. Derycke, P. Fonteneau, P. Soukiassian, Phys. Rev. B 62 (2000) 12660

[17] P. Soukiassian, H. Enriquez, J. Phys. Condens. Matter 16 (2004) S1611.

[18] A. Tejeda, E. Wimmer, P. Soukiassian, D. Dunham, E. Rotenberg, J.D. Denlinger, E.G. Michel, Phys. Rev. B 75 (2007), 195315.

[19] V.Yu. Aristov, H. Enriquez, V. Derycke, P. Soukiassian, G. Le Lay, C. Grupp, A. TalebIbrahimi, Phys. Rev. B 60 (1999) 16553.

[20] V.Yu. Aristov, P. Soukiassian, A. Catellani, R. Di Felice, G. Galli, Phys. Rev. B 69 (2004), 245326.

[21] A. Catellani, G. Galli, F. Gygi, Phys. Rev. B 57 (1998) 12255.

[22] W. Lu, P. Krüger, J. Pollmann, Phys. Rev. Lett. 81 (1998) 2292.

[23] V. Derycke, P. Fonteneau, N.P. Pham, P. Soukiassian, Phys. Rev. B 63 (2001), 201305 (R).

[24] L. Douillard, O. Fauchoux, V. Yu, Aristov and P. Soukiassian, Appl. Surf. Sci. 166 (2000) 220.

[25] V.Yu. Aristov, L. Douillard, O. Fauchoux, P. Soukiassian, Phys. Rev. Lett. 79 (1997) 3700.

[26] P. Soukiassian, F. Semond, A. Mayne, G. Dujardin, Phys. Rev. Lett. 79 (1997) 2498.

[27] P. Soukiassian, V.Yu. Aristov, L. Douillard, F. Semond, A. Mayne, G. Dujardin, L. Pizzagalli, C. Joachim, B. Delley, E. Wimmer, Phys. Rev. Lett. 82 (1999) 3721.

[28] W. Lu, P. Krüger, J. Pollmann, Phys. Rev. Lett. 82 (1999) 3722.

[29] X. Peng, P. Krüger, J. Pollmann, New J. Phys. 10 (2008), 125028. 